UDK 021.84:004

\section{Elektroninių leidinių privalomieji egzemplioriai}

Juha HAKALA

Helsinkio universiteto biblioteka, P.O.Box 26 (Teollisuuskatu 23), Fin-00014,

el. paštas: Juha.Hakala@helsinki.fl

Daug medžiagos. vertingos nacionalinei kultūrai, jau skelbiama on-line. Jos kiekis tinkle nuolat auga, nors gyvavimo laikas dažnai yra labai trumpas. Tuo tarpu komerciniul leidiniu leidejai reikalautja, had cgzistuotı atsakomybė už ju elektroninés medžiagos ilgalaik saugojima. Tačiau tuomet. kai leidinys netenka komercinès vertès arba leidykla užsidaro. jo išlikimas nebegali būti garantuotas.

Niekas nenori inttis atsakonnybés už leidiniu, laisvai preinanny on-line, saugojima. Todèl labai svarbu. kad kuo greičiau išsprestas.

Vienas pagrindiniıł darbo grupés, kuria pasiūlè Suomijos švietimo ministerija, likslụ buvo išplésti veikianti Sriva jo

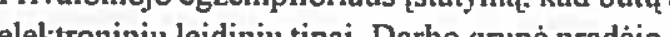
elektroninių leidinit tipal. Darbo grupe pradéjo savo veikla susipažindama su privalomojo cgzcnplioriaus jstatymais, galiojanciais Standinavjos salyse, ir su sil̨ šaliu

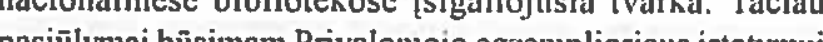
pasiulymai basiman Privalomojo cgzemplioriaus istatymui Suomijoje nebuvo parengti kill Skandinavijos šalit pagrindu, kadangi spartus Iechnologiju vystymasis daro
didžiule jtaką sprendimu prièmimui.

Istatymo aprèptis

Darbo grupès pasiūlymai būsimam istatymui apima ir medžiaga. isleista fizineje laikinenoje (off-line istekhiai). on-line, t. y. medžjaga, paskelbta arba prieinama tinkle.

Atsižvelgiant i istatymo aprépli. nepaprastai svarbu vartoti termina „leidinys" tiek siauraja prasme, kaip jis vartojamas Autoriaus teisès istatyme, tiek platesne prasme. kai kalbama apie medžiaga, prieinamą visuomenei per kompiuterių tinklus.

Norint išplettoti cgzistuojanti Privalomojo egzemplioriaus istatyma, kad jis aprepty visus on-line leidinius, reikia atidžiai jsigilinti. Jci privalonas Suonijos dokumentu, esančì tinkle. pristatymas bus taikomas kiekvienan leidiniui, leidèju. atsakingu už ju pristatymą. skex̌ius love dešimčiı. gal net šmtu tükstančìu. Praktiškai bus sunku informuoti visus leidèjus apic naujaji istatyma, net jei užduociai palengvint bus varojamas internetas, kaip tai buvo padaryta Danjjoje, kur Nacionaliné biblioteka vartoja gerai suprojektuola serveri privalomiesiems egzemplioriams (littp:/wnww.pligtaflering.dk/). Jeigu atsitiktu taip, kad bütu susisiekta su visais leidèjais. kurie turi pristatyt

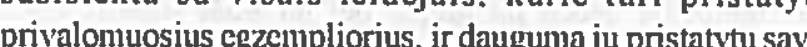
Icidinius bibliotekai. jai tektu padidinti savo personala kad visi leidiniai bütu itraukti i duomeny baze ir bütu gara, kad galimybè prieiti prie ju kitu būdu.

\section{Laisvai prieinami on-line leidinlai}

Norint apriboti leideju. kurie turi pristatyt privalonosus cgempliorius staiči ir sumažin privalom egzempliorius, skaičiu ir sumažin papildomo personalo poreiki nacionalineje bibliotekoje. buvo nition itraukti i pasiūlymus büsimajam privalomojo egzemplioriaus jstatymui. Nepaisant to. Nacionalinei bibliotekai turèt büti suleikta teisè kaupti laisvai prieinamus leidinius is tinklo, pritaikius specialią surinkimo programą. Toki leidiniai gali büti prieinami visuomenei kaip ir kit elcktroniniu leidiniy privalomieji egzemplioriai. Leidinia bus itraukti $i$ viso teksto duomenı̨ baz̨̧, kuri gali būt prieinama isuomenei, tačiau prieiga prie paties dokumento bus apribota. Duomeny kaupimo, saugojimo bei duomen bazés eksploatavino užduotis vykdys Nacionalinè bibliotek (Helsinkio universiteto biblioteka) arba jos igaliotasis atstovas.

Kitų šaliu privalomojo egzemplioriaus istatymuose nebuvo numatyta teisé kaupti laisvai prieinamus on-line leidinius. Taip apsispresesta dèl to kad technologija kurios reikia surinkimo programai ir leidiniu itraukimui, yra laba moderni ir daugiausia ir leidiniu itraukimui, yra labai moderni ir daugiausia prieinama tik komercinems ompanijonss. Be to, tokil leidiniu reikšmingumas buvo aiskiai suprastas tik per pastaruosius kelerius metus. Suomujoje prieiga prie atitinkamu programu pasirodè ideali, kadangi Siauress tinklo indeksu (Nordic Web Index) ir Šauré (Archo arclyvo (Nordic Web Archive) projektai buvo sukurt on-line leidiniai valstybiniu lygiu jau buvo viena karta kaupiami Mokslinio kompiuterizavimo centre (Centre of Scientific Computing - CSC) EVA projektui. Jie sudaro 1.5 milijono dokumentu (25 gigabaitu), kurie šiuo metu yra saugomi CSC juostiniame arclyyve.

CSC kartu su kitais Šiaurès tinklo arclyvo atslovais šiuo metu kuria šĭ Ieidiniu duomenu bazę. Preliminarūs bandymai parodè, kad vartotojui tercikia apie 30 sekundži gauti visiškai adekvatu dokumenta iš juostu archyvo, kadangi šis juostu archyvas yra „paskutinio apsilankymo paslaugos rüšsis. Leidiniu kolekcijos bus atnaujinamos por kartu per metus. Tačiau prircikus (tuo atveju, jei dokumento informacijos turinys keičiasi kasdien) serveriai gali būt plankomi ir daug daz̃niau. Todèl büsimasis istatymas tiksliai neapibréš leidinių kolekcionavimo dažnumo, nes jis gali keistis.

EVA projekto pavyzdys parodè pasiūlymuose sufomuluotu Privalomojo egzemplioriaus istatymo principu funkcionavimo ateityje tvarkant tinkle esančia laisvai prieinama medžiagą teisingumıą Parengiamieji projcktai ir nuleme tokią istatymo formuluotę. Be ju mes bami ganjies pavyzdžiu kur visus on-line leidinius privaloma pristatyti. Per pirnus 10 ménesiu, kai Danijoje pradèjo galioti perzijures istymas, Dauijos karališoji biblioteka gavo 700 dokumentu (400, Duyyo ir 300 s.

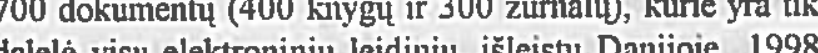
metais.

Off-line ištekliai ir ribotos prieigos on-line medžiaga

Vadovaujantis pasiülytu istalymmu off-line ištekliams suteiktas toks pat statusas kaip ir spausdintiems leidinians, gamintojas yra atsakingas už ju pristatyma, kaip ir spausdintu leidiniu. Svedijoje leidejas lapo atsakingas už pristatyma ir praktine patiris parode. kad gautiCD-ROM diskus iš gamintojo yra nclengva. Suomijoje gauti CDROM diskus iš gamintoju nèra sunku ir šiuo metu privalomieji egzemplioriai pristatomi savanoriškai, todèl mes manème. kad nebūtina sckti švedų pavyzdžiı

Kitą panašuma tarp off-line clektroniniu leidiniu ir spausdintų leidiniu (knygu) gali ižvelgti pačios bibliotekos. Atsakingos už spausdintụ leidiniu katalogavimą bibliotekos kataloguoja ir elektroninius išteklius, pateikdamos informacija i valstybine bibliografija. Suomijos biblioteka

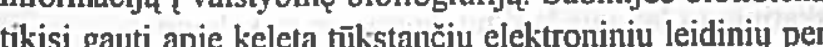
me

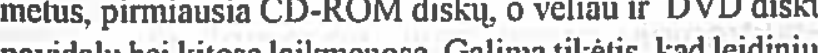
pavidu be kilose kurit pristaty progran zodzį torkmo itraukti i nauja privalomojo egxemplonaus istatyma Pasing suo
Ribotos prieigos on-line leidiniai sudaro labai nevienalytę grupę, apimančia knygos formos leidinius, straipsnius, garso ir vaizdo medžiaga, duomeny bazes. Visais šiais atvejais leidèjas yra atsakingas už pristatyma, tsižvelgiant $i$ tai, had čia nèra atskiro gamintojo.

Pristatymo būdas ir tolimesnis leidiniu tvarkymas bibliotekoje priklauso nuo leidinio formos. Knygos formos leidiniai turi būti tvarkomi vadovaujantis tais pačiais principais kaip ir elektroniniy ištekliu, tuo tarpu elektroniniai straipsniai tvarkomi tik automatizuotai (žr. kita dali).

Vienas svarbiausiu privalomojo egzemplioriaus istatymo principu yra tas, kad elektroniniai leidiniai turi büti pristatyti tokiu formatu ir saugomi tokiame atminties itaise, kuris leistı̣ nacionalinei bibliotekai juos ivesti. Iš esmès elektroninio leidinio formatas ar atminties itaisas, kuriame jis bus saugomas, neturètu būti privalomuju leidiniu atrankos apribojimo kriterijus. Tačiau praktiškai gaunama medžiaga, kuri negali būti jvesta ir naudojama biblioteku. yra bevertè. Pasiülymai būsimam istatymui dél elektronini dokumentu formatu ir atminties itaisu apima šiuos principus:

- Nacionaliné biblioteka palaiko tuos dokumentu formatus, kuriais jie gali būti pristatyti, t. y. SGML, XML, IPEG ir amintes itisus (DAT juosta CD-ROM diskas, DVD diskas);

- leidèjas, kuris privalo pristatyti leidini, turetu konvertuoti ji i priimtiną formata arba nukopijuoti ji i atitinkamą atminties jtaisa jei tai imanoma. Jei konvertuot negalima ar per daug sudètinga, leidiniu pristatyti nereikèty. Tais atvejais, kai leidiniai turi ypatinga vertę ir/ar yra didelés apimties, valstybè turètųą skirti lè̌̌u tinkamai konvertavimo programai sukurt.

Nacionalinei bibliotekai gyvybiškai svarbu, kad būtu išsaugotas originalus dokumento išdèstymas ir apibūdinimai Śtai kodèl dokuınento formatas neturètų būti medžjago atrankos ribojimo kriterijus. To galima būtu išvengt išplečiant galimų formatu ir atminties ttaisu sarašă. Tačiau tuomet kyla sunkumu dé itgalaikio leidiniu saugojimo, nes leidinio konvertavimas gali baigtis dokumento turinio informacijos praradimu irr/ar pastebimais fizinés išvaizdo pasikeitimais. Nacionalinè biblioteka turètu nuspręsti, kokiq apimti galima emuliuoti techuinę ir programine iranga kad ateityje būtu užtikrinta prieiga prie senu leidiniu. Šios srities tyrimai buvo allikti vykdant NEDLIB projekta, kur koordinuoja ES ir kuriame dalyvavo Helsinkio universitetas (nttp://www kb.nl/nedlib/, bei ELIB projekta, pavadint CEDARS (http//www curl be

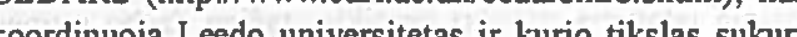
eording Ledo uni

Norint tvarkyti ivairius formatus, kuriais pateikiam privalomieji egzemplioriai, bibliotekoms, kurios juos gauna reiki turèti prieiga prie ivairiu programy dokumentams apdoroti. Prieiga turi tikti ir personalui, kuris kataloguoja medžiaga, ir vartotojams, kurie atlieka paieška duomenu 
bazèje. Bibliotekos personalą, kuris kataloguoja medžiaga ir aptannauja vartotojus, reikia mokyti, kad jis galètu ivykdyti keliamas užduotis

Pristatymo būdai

Elektroniniu dokumentụ pristatymas gali būti tvarkomas taip: leidejas, kuris turi pristatyti privalomuosius egzempliorius, siunčia bibliotekai arba naujausia leidini arba pranešima apie ta leidini. Šiuo arveju bibliatek gauti leidini is leidejo serverio. Privalomojo iszempliorinus istatymas, turis peržiūretas 1998 metu pradžios

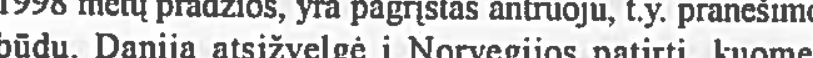
Norvegijos nacionaline bibliote prisegr pristatymo büdu, gavo daugybę netinkanı leidiniu, kuriuos i tinkla pateike individualüs vartotojai. Suomijoje pasiülymai būsimam Privalomojo egzemplioriaus įstatymu neapibrežża pristatymo būdo ar büdụ. Jic turi būti nustatyti remiantis nułarimu, nes pristatymo būdas kinta priklausomai nuo leidinio tipo bei galbut nuo laiko. Skirtingi pristatymo būdai gali būti taikomi lygiagrečiai. Jei būsinasis șstatymas numatys savanorišką laisvai prieinamy on-line leidiniı pristatyma, itraukiant vertingiausius laisvai prieinamus on-line leidinius i valstybinę bibliografija (tai dalis mūsu planu,, tokių leidiniu pristatymas gali būti pagristas pranešimo praktika. Kad pranešimo vartojimas furkkcionuot praktiškai, EVA projekte buvo sukurtos atitinkamos priemones, tokios kaip metaduomeny trafaretai, Pagrindinis tokiu priemoniu kürimo darbas jau buvo atliktas rengiant Siaurés metaduomenu projektą.

Ribotos prieigos on-line leidiniu pristatymas neturètu büti grindžiamas pranešimo vartojimu, kadangi komerciniu leidèju pateikti pranešimai nebus naudojanıi kaip kriterijai, ribojantys atranka. Dar daugiau, pranešimo vartojimas pridès papildomo darbo it nacionalinei bibliotekai (leidinio paieška), ir leidejuri (leidiniu, kurie turi būti pristatyti, aprašymas, ryšio tarp leidèjo ir bibliotekos jvedimas, leidinio atnaujinimas serveryje). Aprošomoji informacija apie leidini gali būti pridèta prie dokumento tačiau leidèjas neturi siusti atskiro pranešimo apie ji.

Straipsniai

Kalbant apie elektroninius straipsnius reikia atkreipti dèmesị $i$ tai, kad pristatymo būdas ir tolesnis apdorojimas bibliotekoje kinta priklausomai nuo leidinio tipo. To i būsima istatymą itraukti nereikia, tačiau darbo grupès âsimaitoje irašyta pastaba rodo, kad ji teikè tam reikšme. Elektroniniai straipsniai, išspausdinti laikraščiuose ir periodiniuose leidiniuose, gali pasirodyti esq svarbiausia leidiniu grupe, kurią aprepia būsimasis şstatymas, todèl tiek daug laiko ir buvo skirta nustatyloms numatomons šlaidoms ir kitiems su jais susijusiems dalykams.
Didžiausi Suomijos laikraščiu ir kitu periodiniu leidiniu leidèjai sukūré išsamias visatekstes duomenu bazes. Dé leidyklu susijungimo $80 \%$ straipsniu, išspausdintu laikraščiuose, buvo itraukta i 3 visatekstes duomeny bazes SGML formatu. Vaizdinè medžiaga saugoma atskiroje duomenụ bazèje kartu su tekstais.

Straipsniu duomenu bazèmis naudojamasi tik bibliotekoje, jos nèra saugomos Naujojo Privasio egzemplioriaus istatymo ivedimas nepakeis situacijos, nebent leidèjas nuspres padaryti straipsnius situacijos, visur leidejas nuspręs padaryti straipsnius prieinamus (n) straipsniu duomeny bazę tinkle ir taip padarydamas ja
privalomą pristatyti.

Kasmet Suomijoje išspausdinama šimtai tūkstančiu laikraščì straipsniu. Tekstu apimtis gigabaitais viršija WW archyvo apimti, prižiūrimą CSC. Iš to galima daryt isvada, kad didžioji dalis straipsniu iki šiol leidžiama BTJ - Kirma

BTJ - Kirjastopalvelu OY prižiūri laikraščiu straipsniy duomenu bazę, tačiau i ją itraukiami tik reikšmingiaus straipsniai. Straipsniy írašai, kuriuos pateikia daugybc biblioleku. yra saugomi ARTO duomenu bazéje, kurioje ivesta apie 1100 žurnalu, 60 000-70 000 straipsniu per metus, Tai tik maža dalelè visų straipsniı, išspausdintu periodiniuose leidiniuose.

Kadangi neimanoma kiekvieną straipsni parengti MARC formatu, vienintelis sprendimas yra pateikti visus straipsnius i duomeny bazes išsamiai

Aukštas techninis leideju vartojamu sistemu lygis leidžia pakankamai lengvai kurti tokias duomenų bazes. Nauji leidiniai gali būti nuskenuoti iš leidèjo duomenų bazés, persiusti $i$ bibliotekos FTP serveri ir naudojantis vadinamaja Automatinés ikelties programa itraukti i bibliotekos duomenu baze. Bibliotekos prižiūrima duomenu baze gal būti tradicinè visateksté, kuriai reikia naudoti SGML sintaksés analizatoriu, arba SGML duomenı̨ bazè. Pastaroji yra pigesné, bet lygiai tokia pat efektyvi.

Apskritai Nacionalineje bibliotekoje sukurti duomenu bazę, kurioje Suomijoje išleisti straipsniai galètụ büti saugomi kaip visateksčiai, pakankamai lengva. Kadangi šaltiniı duomenys yra struktūrizuoti, paieškai duomenı bazèje galima sukurti veiksmingas priemones. Tačiau tam, kad sistema gerai funkcionuotu, biblioteka turi efektyviai bendradarbiauti su leideju. Būtina tokios sistemos salyga bendradarbiauti su leidèju. Bütina tokios sistemos salyga turetu büti leidiniu vartojimo apribojimas vartotoja
skatinimas laikytis leidiniu apsaugos reikalavimu.

Elektroninių privalomuju egzempliorių vartojimas

Spausdintu privalomuju egzemplioriu vartojimo nuostatai pasiülymuose bussimam Privalomojo egzemplioriaus istatymui buvo suformuluoti vadovaujantis jau egzistuojančiais nurodymais. Todèl iš biblioteku, kurios gauna privalomaji egzemplioriu, reikalaujama užtikrinti, kad dokumentais galètı naudotis tick mokslininkai, tiek vis suinteresuoti asmenys. Kadangi bibliotekos nesivadovavo bendromis taisyklémis, vicnose ju privalomuju leidini emplioriai yra lengviau pricinami, kitose sunkiau.

Tam tikru tipu leidiniu spausdintus egzempliorius, pryzdžiui, kuygas ir periodinius leidinius, galima gaut visose depozitinèse bibliotekose. Jei tokiu biblioteku y keletas, reikia tiek pat privalomuju egzemplioriu, nes lidiniai néra prieinami per tinkla.

Tuo tarpu on-line leidiniu nereikia pristatyti keliais egzemplioriais. Jie bus saugomi archyvavimo serveriuo ir atitinkamomis priemonènis juos galima gauti visose šalies depozitinèse bibliotekose

Numatyta, kad Suomijoje rcikès 3 archyvavim。 serveriu:

Serverio laisvai prieinamiems on-line leidiniam

2. Serverio laikrašči ir periodikos straipsniams;

4. Serverio off-line istekliams, pavyzdžiui, CD-R diskams ir ribotos prieigos clektroniniams leidiniams.

Norint apsaugoti ilgalaikio saugojimo leidinius, būtina nukopijuoti off-line išteklius i archyvavimo serverius, nes leidiniu, saugomu tokiose laikmenose, kaip diskeliai, magnetines juostos, amžius yra trumpas. Privalonuju egzemplioriu skaičius pasiūlymuose apribotas iki 2, vienas iu turi būti pristatytas Nacionalinei bibliotekai, o kitas Jyväskylä universiteto bibliotekai.

Labai svarbi yra elektroniniul dokumentu atranka valstybinę bibliografija. Danijoje svarbiu tinklo svetainiu katalogavimo klausimai užima reikšmungą vieta „InDoReg" projekte, kurian vadovauja Danijos biblioteku centras. Šio projekto darbo rezultaty ataskaitoje (http://parl.dk/rappor/ html.uk/) yra idomios informacijos apie kriterijus, kurie taikomi elektroniniams leidinians kataloguoti.

Archyvavimo ir palaikynno serverio sukürimas ir priežiüra yra labai brangus projektas irengti serverius kiekvienoje depozitinèje bibliotekoje, ypač tuo atveju, kai naudotis leidiniu galima per tinklą. Vokiečiu biblioteka nustatè, kad $70 \%$ problemišku leidiniu, t. y. off-line ištekliı, tokił kaip CD-ROM diskai, lengvai gali būti pateikiami tinkle. Apskritai problemišsı leidiniu kiekis mažèja dèl CD-ROM disku programinés irangos modernizavimo.

Leidiniu, kurie turi büti saugomi archyvo serveriuose, komercinè verté bus labai didelè. Pagal naujaji istatymą Nacionaliné biblioteka bus atsakinga už tai, kad elektroniniu leidiniu privalomieji egzemplioriai nebūtu vartojami . Esmis Nausimas - ar tal bus ivykdyta archyvuojant leidinius kaip slaptus ir patvirtintus, ar užtenka padaryt tuos leidinius neprieinamus tiems vartotojams, kurie neturi teisés jais naudotis. Tačiau negalima garantuoti, kad tais leidiniais nebus pasinaudota, nes norint suteikti galimybe teisetai naudotis leidiniais, bütina prijungti serveri prie tinklo.

\section{Išvados}

Svarbu užtikrinti, kad Privalomojo egzemplioriaus istatymas isigaliotu nuo 2000 metu sausio 1 dienos. Jau sudaryti nauju nuostatu idiegimo planai ir kuriamos arba komplektuojamos reikalingos priemonés: VTLS programinè iranga leidžia kataloguoti elektroninius išteklius ir Helsinkio universiteto biblioteka turi elektroniniu leidiniu archyvavimo serveri. Daugelis kitu su tro susijusiu darbu negali būtti pradèti, kol nèra prieigos prie išstekliu, o naujasis istatymas dar neisigaliojo. Po jo prièmimo praeis keleri metai, per kuriuos bus sukutos naujos sistemos. Jei viskas vyks pagal pan depozitinėms bibliotekoms pasidarys kasdienybė.

Iš anglu $\mathrm{k}$. vertè D. Petrauskienè

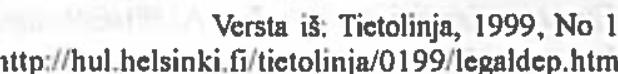

